\title{
Does carbon dioxide insufflation impact adenoma detection rate? A single-center retrospective analysis
}

Authors

Institutions
Yaseen B. Perbtani ${ }^{1}$, Michael Riverso ${ }^{1}$, Jonathan J. Shuster ${ }^{2}$, Joydeep Chakraborty ${ }^{1}$, Tony S. Brar ${ }^{1}$, Mitali Agarwal ${ }^{1}$, Han Zhang ${ }^{1}$, Anand Gupte ${ }^{3}$, Shailendra S. Chauhan ${ }^{3}$, Christopher E. Forsmark ${ }^{3}$, Peter V. Draganov ${ }^{3}$, Dennis Yang ${ }^{3}$

${ }^{1}$ Department of Medicine, University of Florida, Gainesville, Florida, United States

${ }^{2}$ Department of Health Outcomes and Policy University of Florida, Gainesville, Florida, United States

${ }^{3}$ Division of Gastroenterology, University of Florida, Gainesville, Florida, United States submitted 30. April 2016 accepted after revision 12. September 2016

\section{Bibliography}

Dol http://dx.doi.org/ 10.1055/s-0042-118177 Published online: 24.11 .2016 Endoscopy International Open 2016; 04: E1275-E1279

(c) Georg Thieme Verlag KG Stuttgart · New York E-ISSN 2196-9736

\section{Corresponding author} Dennis Yang, MD

Division of Gastroenterology, University of Florida 1329 SW 16th Street, Suite 5251

Gainesville, FL 32608 United States

Phone: +1-352-273-9474

Fax: +1-352-627-9002

Dennis.Yang@medicine.ufl.edu
Background and study aims: Carbon dioxide $\left(\mathrm{CO}_{2}\right)$ has been associated with reduced post-procedural pain and improved patient satisfaction when compared to air insufflation (AI). The effect of $\mathrm{CO}_{2}$ insufflation $\left(\mathrm{CO}_{2} \mathrm{I}\right)$ on the adenoma detection rate (ADR) remains unclear. The aims of this study are to compare ADR in patients undergoing screening colonoscopy with $\mathrm{AI}$ vs. $\mathrm{CO}_{2} \mathrm{I}$ and identify predictors of ADR.

Patients and methods: Single-center retrospective cohort study of 2,107 patients undergoing screening colonoscopy at the University of Florida Hospital between November 2011 and June 2015. Patient demographics, procedural parameters, and histology results were retrospectively obtained from a prospectively maintained colonoscopy database. Univariate and multivariate analysis were performed to identify predictors of ADR.

\section{Introduction \\ $\nabla$}

Colorectal cancer (CRC) remains the second leading cause of cancer death in the United States. Colonoscopy has been shown to reduce risk of death from CRC through the prompt identification and removal of premalignant adenomas or early stage cancerous lesions [1]. Indeed, the increased utilization of screening colonoscopy has been associated with a $30 \%$ reduction in cancer deaths due to CRC in the past decade [2]. Yet the reported impact of colonoscopy on CRC incidence has been widely variable, presumably due to discrepancies in the quality of the procedure [3]

The adenoma detection rate (ADR), defined as the proportion of screening colonoscopies performed by a provider with the detection of at least 1 histologically confirmed adenoma or adenocarcinoma, has been emphasized as an important quality indicator for colonoscopy, given the supporting evidence on ADR and its impact on CRC [4]. There-
Results: A total of 2107 colonoscopies ( 644 with AI and 1463 with $\mathrm{CO}_{2} \mathrm{I}$ ) were analyzed. Overall ADR was $27.8 \%$. There was no significant difference in ADR between $\mathrm{AI}(27.6 \%)$ vs. $\mathrm{CO}_{2} \mathrm{I}(27.8 \%)(P=$ 0.93 ). Method of insufflation (AI vs. $\mathrm{CO}_{2} \mathrm{I}$ ) was not significantly associated with ADR (OR 0.9; 95\% CI:0.7 -1.2). Older age (OR: 1.02; $95 \% \mathrm{CI}: 1.001-$ 1.03 per year increase), male gender (OR 1.48; 95\% CI: 1.17-1.87), and longer scope withdraw time (OR 1.13; 95\% CI: $1.1-1.16$ per minute) were associated with a higher ADR. Fellow involvement was negatively associated with ADR (OR 0.60; 95\% CI: 0.47-0.77).

Conclusion: ADR was similar between patients who underwent screening colonoscopy with $\mathrm{AI}$ vs. $\mathrm{CO}_{2} \mathrm{I}$. While $\mathrm{CO}_{2} \mathrm{I}$ has been associated with improved patient comfort and post-procedural recovery time, there is no definitive evidence to suggest that this method of luminal distention enhances ADR.

fore, the American Society for Gastrointestinal Endoscopy/American College of Gastroenterology Task Force on Quality in Endoscopy has recently proposed ADR targets of $\geq 30 \%$ in men and $\geq 20 \%$ in women [5]. Furthermore, in the setting of recent data demonstrating a $3.0 \%$ decrease in the risk of interval CRC with each $1.0 \%$ increase in ADR [6], it is not surprising that there has been an increased emphasis on identifying and regulating factors that contribute to variability in adenoma detection and thereby improve quality of colonoscopies among practitioners.

Luminal distention during colonoscopy is necessary to allow adequate inspection of the colonic mucosa. Room air insufflation (AI) traditionally has been the most commonly used method for bowel insufflation during colonoscopy. More recently, there has been increasing data supporting the use carbon dioxide $\left(\mathrm{CO}_{2}\right)$ as an alternate method for luminal distention. $\mathrm{CO}_{2}$ is more rapidly absorbed across the intestines when compared 


\begin{tabular}{|c|c|c|c|}
\hline Variable & $\begin{array}{l}\text { Al } \\
(n=644)\end{array}$ & $\begin{array}{l}\mathrm{CO}_{2} \mathrm{I} \\
(\mathrm{n}=1463)\end{array}$ & $P$ value \\
\hline Age, mean $\pm S D$ (years) & $58.7 \pm 8.9$ & $59.1 \pm 8.7$ & 0.32 \\
\hline $\begin{array}{l}\text { Gender } \\
\text { Male, n (\%) }\end{array}$ & 289 (44.9) & $680(46.5)$ & 0.50 \\
\hline $\mathrm{BMI}$, mean $\pm \mathrm{SD}$ & $32.2 \pm 9.4$ & $31.5 \pm 8.8$ & 0.14 \\
\hline \multicolumn{4}{|l|}{ ASA score } \\
\hline I & $25(3.9)$ & $50(3.4)$ & 0.18 \\
\hline II & $286(44.4)$ & $625(42.7)$ & \\
\hline III & $316(49.1)$ & $719(49.2)$ & \\
\hline IV & $17(2.6)$ & $69(4.7)$ & \\
\hline Fellow involvement, $\mathrm{n}(\%)$ & $320(49.7)$ & $553(37.8)$ & $<.001$ \\
\hline \multicolumn{4}{|l|}{ Bowel preparation grading } \\
\hline Excellent & $104(16.2)$ & $187(12.8)$ & 0.0016 \\
\hline Good & $386(59.9)$ & $836(57.1)$ & \\
\hline Fair & $111(17.2)$ & $320(21.9)$ & \\
\hline Poor & $43(6.7)$ & $120(8.2)$ & \\
\hline Cecal intubation rate, $\mathrm{n}(\%)$ & $638(99.1)$ & $1437(98.2)$ & 0.14 \\
\hline Total procedure time, mean \pm SD (minutes) & $20.9 \pm 9.9$ & $19.6 \pm 9.6$ & 0.0022 \\
\hline Scope withdrawal time, mean \pm SD (minutes) & $10.2 \pm 6.9$ & $9.4 \pm 6.4$ & 0.023 \\
\hline
\end{tabular}

Table 1 Study population.

$\mathrm{Al}$, air insufflation; $\mathrm{CO}_{2} \mathrm{l}$, carbon dioxide insufflation; $\mathrm{SD}$, standard deviation.

to air and it has been shown in a large meta-analysis to be associated with a reduction in procedure-related pain [7-10]. However, data are limited on the impact of $\mathrm{CO}_{2}$ insufflation $\left(\mathrm{CO}_{2} \mathrm{I}\right)$ on ADR. The aim of this study was to (1) compare ADR in patients undergoing screening colonoscopy with $\mathrm{CO}_{2} \mathrm{I}$ versus $\mathrm{AI}$ and to (2) identify factors influencing ADR in patients undergoing screening colonoscopy in a tertiary-care endoscopy unit.

\section{Patients and methods \\ $\nabla$}

\section{Study design and patients}

The study was approved by the institutional review board (IRB) of the University of Florida in which a waiver for informed consent was obtained. To be eligible for inclusion in this report, the endoscopic database at the University of Florida Health (UF Health) was retrospectively searched for all patients who had undergone a screening colonoscopy between November 2011 and June 2015. Eligibility was restricted to those with average CRC risk. Patients were excluded if they had a personal or firstdegree relative family history of CRC, history of colon polyps, inflammatory bowel disease, gastrointestinal bleeding, prior history of partial colon resection, and/or an aborted procedure (i.e. due to unsatisfactory bowel preparation, patient intolerance, procedure-related factors) based on information from the endoscopic database and/or electronic chart record. Informed procedural consents were obtained from all patients.

\section{Colonoscopy procedure}

All patients underwent screening colonoscopies by 1 of the 24 experienced board-certified gastroenterologists or by gastroenterology fellows (first- to third-year of fellowship training) under direct supervision of a staff attending. The bowel preparation agent used was predominantly $4 \mathrm{~L}$ of polyethylene glycol solution. Bowel preparation quality was rated as excellent, good, fair, or poor based on the Aronchick scale [11]. All colonoscopies were performed under provider-anesthesiologist-administered conscious sedation (fentanyl and midazolam) or propofol sedation. Cecal intubation was documented by the endoscopist using landmark descriptions (i.e. identification of the ileocecal valve and/or appendiceal orifice). Total procedure time (defined as amount of time from scope insertion to scope removal from the patient) and withdrawal time (defined as the amount of time spent examining the mucosa as the colonoscope is withdrawn) were recorded prospectively and documented in the electronic report by the nurses. Air insufflation was used for luminal distention in all screening colonoscopies prior to January 21st, 2013. Following that date, routine use of $\mathrm{CO}_{2}$ for insufflation was adopted universally for all endoscopic procedures in our institution.

\section{Data collection}

Demographic information and histopathology reports were obtained from chart review. Patient demographics included age, sex, American Society of Anesthesiology (ASA) physical status grade, and body mass index (BMI). Adenomas were classified as tubular, tubulovillous, villous or carcinoma based on the Vienna criteria [12]. Dysplasia was defined as either low-grade or highgrade. Colonoscopy-related data obtained from the prospectively maintained report generating database included: type of sedation, quality of bowel preparation, fellow involvement, cecal intubation, total procedure time, withdrawal time, and number of polyps removed. Endoscopic adverse events (AEs) were defined based on previously established criteria by the American Society of Gastrointestinal Endoscopy (ASGE) [13]. AEs were determined by reviewing the colonoscopy report and the immediate postprocedural note.

\section{Study outcomes}

The primary aim of this study was to compare the ADR in patients undergoing screening colonoscopy with $\mathrm{AI}$ versus $\mathrm{CO}_{2}$ I. ADR was defined as the proportion of colonoscopies in which at least 1 histologically confirmed adenoma was detected. A secondary aim was to identify factors associated with ADR in our cohort.

\section{Statistical methods}

Baseline characteristics for Table 1 between the 2 cohorts AI and $\mathrm{CO}_{2} \mathrm{I}$ were compared by (a) the Student's $t$-test with the Satterthwaite correction for unequal variances for quantitative variables (age, BMI, total procedure time, and scope withdrawal time); (b) Pearson's chi-square for binary variables (gender, fel- 


\begin{tabular}{|lcccc|}
\hline Pathology & $\begin{array}{l}\text { Al } \\
(\mathbf{n = 6 4 4 )}\end{array}$ & $\begin{array}{l}\mathrm{CO}_{\mathbf{2}} \mathbf{I} \\
(\mathbf{n = 1 4 6 3 )}\end{array}$ & OR (95\% Cl) & P value \\
\hline Tubular adenoma, $\mathrm{n}(\%)$ & $156(24.22)$ & $379(25.91)$ & $0.91(0.74-1.13)$ & 0.41 \\
\hline Tubulovillous adenoma, $\mathrm{n}(\%)$ & $23(3.57)$ & $50(3.42)$ & $1.05(0.63-1.73)$ & 0.86 \\
\hline Villous adenoma, $\mathrm{n}(\%)$ & $5(0.78)$ & $4(0.27)$ & $2.85(0.76-10.66)$ & 0.10 \\
\hline Adenocarcinoma, $\mathrm{n}(\%)$ & 0 & $5(0.34)$ & - & 0.14 \\
\hline
\end{tabular}

Table 2 Histologic classification of adenomatous polyps.

$\mathrm{Al}$, air insufflation; $\mathrm{CO}_{2} \mathrm{I}$, carbon dioxide insufflation.

\begin{tabular}{|c|c|c|c|c|c|}
\hline \multirow[t]{2}{*}{ Clinical variable } & \multicolumn{2}{|l|}{ Univariate analysis } & \multicolumn{2}{|l|}{ Multivariate Analysis } & \multirow{2}{*}{$\begin{array}{l}\text { Table } 3 \text { Factors associated with } \\
\text { ADR. }\end{array}$} \\
\hline & OR (95\% Cl) & $P$ value & OR (95\% Cl) & $P$ value & \\
\hline Age (years) & $1.02(1.004-1.026)$ & .0067 & $1.02(1.001-1.028)$ & 0.034 & \\
\hline Gender (male vs. female) & $1.56(1.29-1.89)$ & $<.001$ & $1.48(1.17-1.87)$ & 0.001 & \\
\hline $\operatorname{BMI}\left(\mathrm{kg} / \mathrm{M}^{2}\right)$ & $1.00(0.99-1.01)$ & 0.87 & $1.01(0.99-1.02)$ & 0.51 & \\
\hline $\begin{array}{l}\text { ASA score } \\
1 \text { vs. } 2,3 \text { and/or } 4\end{array}$ & $1.56(0.88-2.77)$ & 0.13 & $1.61(0.84-3.12)$ & 0.15 & \\
\hline $\begin{array}{l}\text { Type of sedation } \\
\text { (conscious sedation vs. propofol) }\end{array}$ & $0.99(0.81-1.22)$ & 0.93 & $1.02(0.71-1.45)$ & 0.93 & \\
\hline Fellow involvement (yes vs. no) & $1.00(0.82-1.21)$ & 0.98 & $0.60(0.47-0.77)$ & $<.001$ & \\
\hline $\begin{array}{l}\text { Quality of bowel preparation } \\
\text { (excellent vs good/fair/poor) }\end{array}$ & $1.43(1.06-1.92)$ & 0.018 & $1.37(0.96-1.96)$ & 0.087 & \\
\hline Cecal intubation (yes vs. no) & $2.10(0.80-5.47)$ & 0.13 & $1.18(0.23-5.94)$ & 0.84 & \\
\hline Total procedure time (Min) & $1.06(1.05-1.07)$ & $<.001$ & $1.01(0.99-1.02)$ & 0.55 & \\
\hline Scope withdrawal time (Min) & $1.13(1.11-1.15)$ & $<.001$ & $1.13(1.10-1.16)$ & $<.001$ & \\
\hline Type of insufflation (Al vs. $\mathrm{CO}_{2} \mathrm{I}$ ) & $0.99(0.81-1.22)$ & 0.93 & $0.90(0.69-1.17)$ & 0.41 & \\
\hline
\end{tabular}

$\mathrm{Al}$, air insufflation; $\mathrm{CO}_{2} \mathrm{l}$, carbon dioxide insufflation.

low-involvement, cecal intubation); and (c) the Wilcoxon test for ordinal variables (ASA score and Bowel preparation grading).

Univariate analysis for $\bullet$ Table 2 and $\bullet$ Table 3 was conducted by univariate and multiple logistic regression. The odds ratios for the quantitative independent variables in Table 3 reflect the ratio of odds, for 2 subjects with 1 with a value 1 unit higher than the other, but otherwise equivalent on other covariates in the model, if any, higher value to lower value. The multivariate model estimates the odds ratio (and compares it to the null value of 1.00) adjusting for all other variables in the model. Significance in the multiple regression model means that the variable has independent significant prognostic value that cannot be accounted for by the other variables in the model.

All $P$ values are 2-sided. SAS (Statistical Analysis Systems) version 9.4 was used in all of the analyses.

\section{Results}

\section{Study population}

A total of 2107 screening colonoscopies were performed among the eligible patients during the study period. Of these colonoscopies, 644 (30.6\%) were performed with AI compared to 1463 (69.4\%) with $\mathrm{CO}_{2} \mathrm{I}(-$ Table 1$)$. There were no significant differences in age, gender, BMI or ASA score between patients undergoing colonoscopy with $\mathrm{AI}$ vs. $\mathrm{CO}_{2} \mathrm{I}$. The cecal intubation rate was also similar between the 2 groups $(99.1 \%$ in the AI group vs. $98.2 \%$ in the $\mathrm{CO}_{2} \mathrm{I}$ group; $P=0.14$ ). The total procedure time and scope withdrawal time were slightly longer in patients undergoing colonoscopy with $\mathrm{AI}$ vs. $\mathrm{CO}_{2} \mathrm{I}$. Fellows were more commonly involved in colonoscopies with $\mathrm{AI}(49.7 \%)$ vs. $\mathrm{CO}_{2} \mathrm{I}$ $(37.8 \%)(P<0.001)$. The average scope withdrawal time was longer when a fellow was involved/present during the procedure $(11.5 \pm 7.5 \mathrm{~min}$ vs. $8.3 \pm 5.5 \mathrm{~min} ; P<0.001)$. Cumulatively, the quality of the bowel preparation was rated better in patients undergoing colonoscopies with $\mathrm{AI}$ vs. $\mathrm{CO}_{2} \mathrm{I}(P=0.0016)$.

\section{Adenoma detection rate}

Overall, a total of 622 adenomatous lesions were detected in this study. The cumulative ADR in this study was $27.8 \%$. There was no statistically significant difference in the ADR in patients undergoing colonoscopy with $\mathrm{AI}(178 / 644 ; 27.6 \%)$ vs. $\mathrm{CO}_{2} \mathrm{I}(407 / 1463$; $27.8 \%)(P=0.93)$. The histologic classification of the adenomatous polyps detected was also similar in both groups ( Table2). Overall, tubular adenoma was the most common histopathology reported for both groups $(P=0.41)$. There were a total of 5 adenocarcinomas diagnosed on histopathology, all from patients who underwent $\mathrm{CO}_{2} \mathrm{I}(P=0.14)$. Only a small number of adenomas detected during colonoscopies with $\mathrm{AI}(4.3 \%)$ and $\mathrm{CO}_{2} \mathrm{I}(3.9 \%)$ revealed high-grade dysplasia (OR 0.89; $95 \% \mathrm{CI}: 0.38-2.09$ ).

\section{Factors associated with ADR}

Univariate and multiple logistic regression analyses were performed to identify factors associated with ADR ( $\bullet$ Table 3 ). The variables included were age, gender, BMI, fellow involvement (yes vs. no), cecal intubation (yes vs. no), scope withdrawal time, total procedure time, type of sedation (conscious sedation vs. propofol), quality of bowel preparation and method of bowel insufflation ( $\mathrm{AI}$ vs $\mathrm{CO}_{2} \mathrm{I}$ ). Patient characteristics, including older age and male gender, were associated with a higher ADR in both univariate and multivariate analysis. While both scope withdrawal time and total procedure time correlated positively with ADR on univariate analysis, only scope withdrawal time was found to positively impact ADR on multivariate analysis. Neither type of sedation nor method of bowel insufflation $\left(\mathrm{AI}\right.$ vs. $\left.\mathrm{CO}_{2} \mathrm{I}\right)$ had a significant association with ADR. Quality of bowel preparation was also not significantly associated with ADR (OR 1.37; $95 \% \mathrm{CI}$ : $0.96-1.96)$. On the other hand, fellow involvement during the 
colonoscopy was the only covariate that was negatively associated with ADR on multivariate analysis.

\section{Adverse events}

There were no procedural or sedation-related AEs reported in the prospective colonoscopy database or in the immediate postoperative note on chart review. Overall, 28 procedures (1.3\%) were aborted due to inadequate bowel preparation and/or tortuous colon as indicated on the colonoscopy report. There were a total of 6 cases terminated prematurely due to patient discomfort. Out of these, 4 cases were done with AI vs 2 with $\mathrm{CO}_{2} \mathrm{I}$ $(P=0.07)$.

\section{Discussion \\ $\nabla$}

Colonoscopy is considered the gold standard for CRC screening. The effectiveness of this strategy at reducing the morbidity and mortality associated with CRC is dependent on optimal detection and resection of premalignant or early stage cancerous lesions. Hence, ADR is currently regarded as the most important measure of quality in colonoscopy. In this study, there was no difference in ADR in patients undergoing screening colonoscopy with AI versus those with $\mathrm{CO}_{2} \mathrm{I}$ after adjusting for patient and procedural variables.

AI is the most commonly utilized method for colonic insufflation during colonoscopy. More recently, alternate methods of luminal distention, such as water-assisted colonoscopy and $\mathrm{CO}_{2} \mathrm{I}$, have been sought as to reduce post-procedural patient pain and bloating associated with AI. Yet the current literature on methods of bowel distention and its effect on ADR is scarce. In a recent Cochrane review, Hafner et al. compared technical quality and screening efficacy between patients undergoing AI versus water infusion during colonoscopy [14]. Their analysis, which included 16 randomized controlled trials consisting of 2933 colonoscopies, showed a slight improvement in ADR with water infusion vs. AI (risk ratio 1.16; $95 \% \mathrm{CI}: 1.04-1.30, P=0.007$ ). It has been speculated that this increase in ADR may be secondary to additional bowel lavage with water infusion, with the drawback of significantly longer insertion time [15]. Conversely, the previous literature on the impact of $\mathrm{CO}_{2} \mathrm{I}$ on $\mathrm{ADR}$ has been limited to a single abstract submission by Mills and colleagues[16]. The preliminary results from their retrospective review suggested a higher $\mathrm{ADR}$ in patients with $\mathrm{CO}_{2} \mathrm{I}$ vs. AI for colonoscopy (OR 1.36; $95 \% \mathrm{CI}$ : $1.01-1.85)$. However, information on whether and how these findings were adjusted for other potential confounding factors was unavailable, which makes the interpretation of their results difficult. In our study of 2107 screening colonoscopies, there was no significant difference in ADR between patients undergoing the procedure with AI vs. $\mathrm{CO}_{2}$ I. Furthermore, method of bowel insufflation (AI vs. $\mathrm{CO}_{2} \mathrm{I}$ ) was not found to be significantly correlated with ADR (OR 1.12; 95\% CI: 0.87-1.45) after adjusting for patient characteristics (age, gender, BMI) and procedural variations (fellow involvement, cecal intubation rate, type of sedation, quality of bowel preparation, total procedure and scope withdrawal time). Nonetheless, while our current data did not demonstrate a potential advantage of $\mathrm{CO}_{2} \mathrm{I}$ over $\mathrm{AI}$ on $\mathrm{ADR}$, several other studies have alluded to the benefits of $\mathrm{CO}_{2} \mathrm{I}$ in terms of patient comfort and satisfaction $[10,17,18]$. Congruent with prior findings, in this study we demonstrated that a slightly higher number of cases cancelled due to patient discomfort when the procedure was performed with $\mathrm{AI}$ vs. $\mathrm{CO}_{2} \mathrm{I}$; albeit this difference did not quite reach statistical significance $(P=0.07)$. In general, patient acceptability and tolerability would intuitively seem to improve the efficacy of the procedure. Whether the overall widely reported positive perception and attitude towards $\mathrm{CO}_{2} \mathrm{I}$ during colonoscopy actually translates to higher compliance and thereby effective screening remains to be determined.

Differences in patient demographics and procedure-related factors have varying effects on the ADR. Both older age and male gender have been shown to be independently associated with a higher ADR on previous studies $[19,20]$. Our results are in line with these prior reports as both increasing age and male gender positively correlated with ADR. Similarly, procedural process measures, particularly scope withdrawal time, have been linked with ADR and hence the quality of the examination. In a landmark study by Barclay and colleagues, mean withdrawal times of 6 minutes or more were found to have higher rates of detection of neoplasia $(28.3 \%$ vs. $11.8 \%, P<0.001)$ [21]. Several other studies have further confirmed a linear correlation between withdrawal time and ADR $[22,23]$. In our study, the mean withdrawal time was more than 6 minutes in patients undergoing colonoscopy irrespective of method of insufflation. Congruent with prior studies, this study demonstrated that longer scope withdrawal time was associated with a higher ADR (OR 1.13; 95\% CI: $1.1-1.16)$. Our findings further corroborate the importance of withdrawal time as a surrogate marker for the thoroughness and quality of the examination for the detection of neoplastic lesions during colonoscopy.

In this study, fellow involvement was associated with a decrease in ADR in multivariate analysis ( $\bullet$ Table 3 ). The current available data on the effect of fellow involvement in colonoscopy on ADR is conflicting, with some studies supporting a positive correlation [24], whereas others suggesting no effect or a lower ADR [25]. This discrepancy among studies may be in part associated with differences in the level of training of fellows included as well as with the degree of supervision provided by the staff endoscopist at the time of the procedure. In this study, fellow involvement was negatively associated with ADR even though the average withdrawal time was significantly longer when a fellow was present. Future prospective studies are needed to clarify the association between fellow involvement and ADR. This is not only imperative in order to maintain quality of care but also to identify benchmarks during colonoscopy training.

Our findings should be interpreted in light of the strengths and limitations of the study. The main strengths of our study are the comprehensive and detailed assessment of ADR in 2107 colonoscopies performed in our institution. Multiple established quality indicators were all collected prospectively over a 4-year period and included in our analysis. Our findings on the effect of patient demographics (age, gender) and procedure parameters (scope withdrawal time) on ADR are in line with those previously reported and allude to the validity of the study. Furthermore, this is the first study evaluating the impact of $\mathrm{CO}_{2} \mathrm{I}$ vs. $\mathrm{AI}$ on ADR. Our findings suggest that $\mathrm{CO}_{2} \mathrm{I}$ did not significantly correlate with ADR after adjusting for patient and procedural covariates. With the increasing number of reports supporting the use of $\mathrm{CO}_{2} \mathrm{I}$ for endoscopic procedures in regards to patient comfort and postprocedural recovery, further prospective studies evaluating its effect on ADR and thereby the effectiveness of the colonoscopy are needed. We also recognize the limitations of our study. First, the study was performed in a single tertiary care center and results may not be generalizable to all ambulatory endoscopic units. Furthermore, this was a retrospective study with its inher- 
ent limitations, including baseline differences in rate of fellow involvement, quality of bowel preparation, and procedural time between patients undergoing colonoscopy with $\mathrm{AI}$ vs. $\mathrm{CO}_{2} \mathrm{I}$. Nonetheless, the effect of these variables was adjusted by performing a multivariate analysis to specifically determine whether any of the confounding variables contributed specifically to the ADR. Furthermore, data on the type of colonoscopes (i.e. standard definition vs. high-definition) used in this study was not readily available in the final analysis. Our ongoing data extraction suggests that close to $90 \%$ of all cases in both groups were performed with high-definition colonoscopes (data not shown). While we recognize that differences in the type of colonoscopes between the 2 groups may affect the interpretability of our findings, its impact on polyp or adenoma detection rate remains debatable based on the conflicting literature [26-28]. Lastly, while the adequacy of bowel cleansing has been clearly linked to ADR, the quality of bowel preparation was not significantly associated with ADR in our study (OR 1.4; 95\% CI: 0.96-1.96). This difference could potentially be explained by the bowel cleansing grading used in this cohort (Aronchick scale), which was specifically designed and validated to compare the efficacy of purgatives rather than outcomes such as ADR.

\section{Conclusion}

\section{$\nabla$}

In conclusion, this study demonstrates that the detection of adenomatous polyps in preventive colonoscopy was not significantly increased by the use of $\mathrm{CO}_{2} \mathrm{I}$ compared to AI. While the implementation of $\mathrm{CO}_{2} \mathrm{I}$ has been clearly associated with improved patient comfort and post-procedural recovery time, there is no definitive evidence to suggest that this method of luminal distention enhances ADR. Future prospective trials are needed to compare the effect of different methods of luminal distention on ADR and on the overall effectiveness of screening colonoscopy.

\section{Competing interests: None}

\section{Acknowledgements}

Research reported in this publication was partly supported by the National Center For Advancing Translational Sciences of the National Institutes of Health under Award Number UL1TR001427. The content is solely the responsibility of the authors and does not necessarily represent the official views of the National Institutes of Health.

\section{References}

1 Zauber AG, Winawer SJ, O'Brien MJ et al. Colonoscopic polypectomy and long-term prevention of colorectal-cancer deaths. N Engl J Med 2012; 366: 687-696

2 Siegel R, Desantis C, Jemal A. Colorectal cancer statistics, 2014. CA Cancer J Clin 2014; 64: 104 - 117

3 Pohl H, Robertson DJ. Colorectal cancers detected after colonoscopy frequently result from missed lesions. Clin Gastroenterol Hepatol 2010; 8: $858-864$

4 Kaminski MF, Regula J, Kraszewska $E$ et al. Quality indicators for colonoscopy and the risk of interval cancer. N Engl J Med 2010; 362: $1795-1803$

5 Rex DK, Schoenfeld PS, Cohen J et al. Quality indicators for colonoscopy. Gastrointest Endosc 2015; 81: $31-53$
6 Corley DA, Jensen CD, Marks AR et al. Adenoma detection rate and risk of colorectal cancer and death. N Engl J Med 2014; 370: 1298-1306

$7 \mathrm{Wu} J, \mathrm{Hu} \mathrm{B}$. The role of carbon dioxide insufflation in colonoscopy: a systematic review and meta-analysis. Endoscopy 2012; 44: 128-136

8 Brandt LJ, Boley SJ, Sammartano R. Carbon dioxide and room air insufflation of the colon. Effects on colonic blood flow and intraluminal pressure in the dog. Gastrointest Endosc 1986; 32: 324-329

9 Yasumasa K, Nakajima K, Endo $S$ et al. Carbon dioxide insufflation attenuates parietal blood flow obstruction in distended colon: potential advantages of carbon dioxide insufflated colonoscopy. Surg Endosc 2006; 20: 587-594

10 Sumanac K, Zealley I, Fox BM et al. Minimizing postcolonoscopy abdominal pain by using $\mathrm{CO}(2)$ insufflation: a prospective, randomized, double blind, controlled trial evaluating a new commercially available CO(2) delivery system. Gastrointest Endosc 2002; 56: 190 - 194

11 Aronchick CA, Lipshutz WH, Wright SH et al. A novel tableted purgative for colonoscopic preparation: efficacy and safety comparisons with Colyte and Fleet Phospho-Soda. Gastrointest Endosc 2000; 52: $346-$ 352

12 Schlemper RJ, Riddell RH, Kato $Y$ et al. The Vienna classification of gastrointestinal epithelial neoplasia. Gut 2000; 47: 251-255

13 Cotton PB, Eisen GM, Aabakken $L$ et al. A lexicon for endoscopic adverse events: report of an ASGE workshop. Gastrointest Endosc 2010; 71: $446-454$

14 Hafner S, Zolk K, Radaelli $F$ et al. Water infusion versus air insufflation for colonoscopy. Cochrane Database Syst Rev 2015; 5: Cd009863

15 Leung FW, Amato A, Ell C et al. Water-aided colonoscopy: a systematic review. Gastrointest Endosc 2012; 76: 657-666

16 Mills CD, Swaine A, Mccamley $C$ et al. Su1686 The impact of carbon dioxide insufflation on colonic polyp and adenoma detection rate. Gastrointestinal Endoscopy 2015: 81

17 Riss S, Akan B, Mikola B et al. CO2 insufflation during colonoscopy decreases post-interventional pain in deeply sedated patients: a randomized controlled trial. Wien Klin Wochenschr 2009; 121: 464-468

18 Wang WL, Wu ZH, Sun Q et al. Meta-analysis: the use of carbon dioxide insufflation vs. room air insufflation for gastrointestinal endoscopy. Aliment Pharmacol Ther 2012; 35: 1145-1154

19 Schramm C, Mbaya N, Franklin J et al. Patient- and procedure-related factors affecting proximal and distal detection rates for polyps and adenomas: results from 1603 screening colonoscopies. Int J Colorectal Dis 2015; 30: $1715-1722$

20 Cai B, Liu Z, Xu Y et al. Adenoma detection rate in 41,010 patients from Southwest China. Oncol Lett 2015; 9: 2073-2077

21 Barclay RL, Vicari JJ, Doughty AS et al. Colonoscopic withdrawal times and adenoma detection during screening colonoscopy. $\mathrm{N}$ Engl J Med 2006; 355: $2533-2541$

22 Jover R, Zapater P, Polania $E$ et al. Modifiable endoscopic factors that influence the adenoma detection rate in colorectal cancer screening colonoscopies. Gastrointest Endosc 2013; 77: 381 - 389.e381

23 Butterly L, Robinson CM, Anderson JC et al. Serrated and adenomatous polyp detection increases with longer withdrawal time: results from the New Hampshire Colonoscopy Registry. Am J Gastroenterol 2014; 109: 417-426

24 Buchner AM, Shahid MW, Heckman MG et al. Trainee participation is associated with increased small adenoma detection. Gastrointest Endosc 2011; 73: $1223-1231$

25 Leffler DA, Kheraj R, Bhansali A et al. Adenoma detection rates vary minimally with time of day and case rank: a prospective study of 2139 first screening colonoscopies. Gastrointest Endosc 2012; 75: $554-560$

26 Burke CA, Choure AG, Sanaka MR et al. A comparison of high-definition versus conventional colonoscopes for polyp detection. Dig Dis Sci 2010; 55: $1716-1720$

27 Tribonias G, Theodoropoulou A, Konstantinidis $K$ et al. Comparison of standard vs high-definition, wide-angle colonoscopy for polyp detection: a randomized controlled trial. Colorectal Dis 2010; Oct 12: e260-266

28 East JE, Stavrindis M, Thomas-Gibson $S$ et al. A comparative study of standard vs. high definition colonoscopy for adenoma and hyperplastic polyp detection with optimized withdrawal technique. Aliment Pharmacol Ther 2008; 28: 768-776 